\title{
Do Taxes Matter in the CAPM?
}

Lutz Kruschwitz, Department of Banking and Finance, Freie Universität Berlin, E-Mail: lutz.kruschwitz@googlemail.com Andreas Löffler, Department of Finance and Investment, Universität Paderborn, E-Mail: andreas.loeffler@googlemail.com

\begin{abstract}
The traditional literature on the CAPM assumes that investor's tax payments simply vanish from the model. This assumption is not at all consistent with the actual behavior of the Treasury. The theory of general equilibrium states that an interest rate $r_{f}=0$ will not affect prices if taxes are introduced. We show that this result can be extended to the CAPM if the tax payments are redistributed among investors.
\end{abstract}

Keywords: CAPM, Tax-CAPM, equilibrium, taxes, CARA utility

Manuscript received June 13, 2009, accepted by Rainer Niemann (Accounting) November 10, 2009.

\section{Presentation of the Problem}

The standard CAPM is a neoclassical equilibrium model based on some simplifying assumptions (see Sharpe 1964, Lintner 1965, and Mossin 1966). In particular, it relies on the assumption that investors base their decisions on the expected value and variance of cash flows with no taxes being collected.

Brennan (1970) was the first to model taxes within a CAPM. His work was the foundation of numerous further contributions. Whereas Brennan analyzed a proportional tax, Litzenberger and Ramaswamy (1979) and Litzenberger and Ramaswamy (1980) looked at a progressive tax. As early as in the $1990 \mathrm{~s}$ Koenig (1990) applied Brennan's model to the tax system that was valid in Germany at that time. More recent analyses taking current German tax regulations into account have been provided by Wiese (2004), Jonas, Loeffler, and Wiese (2004), Wiese (2006a), Wiese (2006b), Rapp and Schwetzler (2007) and Wiese (2007).

It should be emphasized that all these models were single period models in which the investors base their decisions on the $\mu$ - $\sigma$ criterion while assuming risk aversion. When taking a closer look at how taxes are modeled, a circumstance emerges that so far has gone unnoticed. At the end of the period the Treasury collects taxes which are not returned to the taxpayers. For a drastic illustration of this model's peculiarity let us imagine that investors live on an island which once a year is ravaged by pirates who relieve them of taxes, which they will never see again.

This circumstance is hardly compatible with an equilibrium model. Rather, it would appear more appropriate to assume that the tax authorities reinvest their revenue in the form of transfer payments. These include unemployment insurance, pension funds, compulsory health insurance, development aid etc.

In a recent paper Eikseth and Lindset (2009) consider the redistribution of taxes. Surprisingly, they do not report on any effects on the equilibrium security prices. Authors dealing with scientific topics of public finance have also made such assumptions (see, e.g., Konrad 1991 p. 167, Buchholz and Konrad 2000 p. 87). or at least point out that the model analysis responds very sensitively depending on which redistribution system is assumed (see, e.g., Stiglitz 1972 or Rapp and Schwetzler 2008). Konrad analyzes a model where the difference between cash flows and opportunity costs is taxed, whereas in our model cash flow minus depreciation forms the tax base. Konrad de facto looks at a Johansson-Samuelson tax. Seen in this light, our model is closer to the existing national tax codes. Rapp and Schwetzler look at a binomial model where at $t=1$ exactly two states are possible. In this model investors trade on two stock markets that are not connected to each other. The redistribution is given by a random variable. It 
turns out that the specific form of redistribution has an important impact on the asset's prices. In our model the uncertainty is much more general since we allow for multiple states of nature. If one then takes into account that the revenue of the tax authorities is allocated to investors according to a specific rule, then this will impact on the optimal portfolio and hence on equilibrium prices. We must assume that the tax CAPM equations derived by Brennan and others are questionable, at least to the extent that they are based on the unrealistic assumption that the tax revenue vanishes. In the next two sections we wish to show that the equilibrium prices in the CAPM remain unchanged, provided one of the following two requirements is met:

- The risk-free interest rate vanishes.

- Investors have $\mu-\sigma$ utility functions with constant absolute risk aversion.

We are able to provide convincing intuitions for both conclusions.

\section{The Model}

The CAPM is a two-period model, represented by today (time 0 ) and tomorrow (time 1). The future is uncertain. We examine $I$ investors $i=1, \ldots, I$ who trade on a capital market and have individual $\mu-\sigma$ utility functions

\section{(1) $U^{i}\left(\mu, \sigma^{2}\right)$}

depending on expectation and variance of securities' payments. Utility functions like this can be explained through independent axioms for the preferences (see Loeffler 1996b). These utility functions are strictly monotonically increasing in the first variable (expected value $\mu$ ) and strictly monotonically decreasing in the second variable (variance $\sigma^{2}$ ). Moreover, they are quasi-concave, which means that the answers of the individual maximization problems are always unique.

There are $n=0, \ldots, N$ assets with cash flows of $\widetilde{Y}_{n}$ at a specific time $t=1$. These cash flows consist both of dividends and capital gains. The 0 -th asset is the risk-free asset and pays a unit in the next period; all other assets are uncertain. Portfolio $X$ consists of these $N+1$ assets, whereby the $n$-th entry $X_{n}$ designates the number of the $n$-th asset which an investor holds at a specific time $t=0$. The payment of the portfolio $X$ then reads as follows:

$$
X_{0}+\sum_{n=1}^{N} X_{n} \widetilde{Y}_{n}
$$

The amount of the optimal risk-free asset is $X_{0}^{i}$. Accordingly, $X^{i}$ designates the (optimal) risky portfolio of investor $i$, whereby this portfolio is a $N$ dimensional vector with entries $X_{1}^{i}$ to $X_{N}^{i}$.

The vector $E$ includes the $N$ expected values of the payments of the risky assets. The corresponding covariance matrix is $\Omega$ with the dimensions $N \times N$. Hence the expected value of the portfolio $\left(X_{0}^{i}, X^{i}\right)$ is $X_{0}^{i}+X^{i} \cdot E$. The variance is $\left(X^{i}\right)^{T} \cdot \Omega \cdot X^{i}$.

The investors' initial endowment $\left(\bar{X}_{0}^{i}, \bar{X}^{i}\right)$ consists of the risky asset and a share of the riskless asset. For every risky share there is one unit in total; the riskless asset is given in zero net supply, hence

(3) $\quad \sum_{i=1}^{I} \bar{X}_{0}^{i}=0, \quad \sum_{i=1}^{I} \bar{X}_{n}^{i}=1(n>0)$.

We designate the sum of the risky initial endowments as the market portfolio $M$.

The price of a portfolio $X$ is described by the symbol $p(X)$. Hence the budget restriction of an investor reads as follows: $p\left(X_{0}^{i}\right)+p\left(X^{i}\right)=p\left(\bar{X}_{0}^{i}\right)+p\left(\bar{X}^{i}\right)$. There is no arbitrage in the equilibrium. Therefore, the prices are linear. Consequently, there is a vector $p$ which implies that

\section{(4) $\forall X \quad p(X)=p \cdot X$.}

Vector $p$ is not necessarily positive as we are dealing with prices of the basic assets rather than state prices.

We assume that the tax authorities collect a tax on the investors' income. The valuation basis is the difference resulting from the return flows of the optimal portfolio and the capital endowment. Risky and riskless entries are subject to the same linear tax rate $\tau$. Therefore, the $i$-th investor' tax debts amount to

$$
\begin{aligned}
T^{i} & =\tau\left(X_{0}^{i}-p\left(X_{0}^{i}\right)+\sum_{n=1}^{N} X_{n}^{i} \widetilde{Y}_{n}-p\left(X^{i}\right)\right)= \\
& =\tau\left(X_{0}^{i}-p\left(\bar{X}_{0}^{i}\right)+\sum_{n=1}^{N} X_{n}^{i} \widetilde{Y}_{n}-p\left(\bar{X}^{i}\right)\right) .
\end{aligned}
$$

As opposed to Brennan (1970) in our model dividends, capital gains and interest are taxed differ- 
ently. Whether our results will survive with a richer tax system remains to be seen.

The total tax revenues $\sum_{i=1}^{I} T^{i}$ are redistributed to the investors according to a certain rule. The $i$-th investor receives the share $\omega^{i}$ of the entire revenue from taxes, whereby the equation

(6) $\sum_{i=1}^{I} \omega^{i}=1$

applies. Evidently the shares $\omega^{i}$ are then deterministic. If the distribution parameters are accepted as random variables, then any equilibrium could be explained. We know that a certain total amount can be distributed to the investors. If we then wish to attain a special income distribution, we select the $\omega^{i}$ in precisely such a way that in each environmental condition and depending on the payment of the initial endowment, the required financial means can be either allocated to the investors or taken away. This counteracts the distribution mechanism, however.

An equilibrium is characterized by two conditions: Each investor maximizes their individual utility and the markets are cleared. In our model there is another problem which we wish to point out: Based on our assumptions the activity of one investor has, due to the tax returns, an impact on the optimization problem of all other investors.

It would, therefore, be conceivable that investors take the initiative and form coalitions which might initially lead to fictitious equilibria that could attain stability only on the basis of these tax returns. Such equilibria are discussed in the literature as "sunspot equilibrium" (see, for instance Shell (forthcoming)). We wish to rule out such equilibria and therefore assume that - provided the investor has the profit of his utility - he will take a decision that is optimal for the other investors, hence avoiding sunspot equilibria.

Definition 2.1 An equilibrium is described by $a$ price vector $p$ and $a$ demand quantity $\left(X_{0}^{i}, X^{i}\right)_{i=1, \ldots, I}$ with the following two characteristics:

1. Demand $\left(X_{0}^{i}, X^{i}\right)$ maximizes the utility for investor $i$, provided the allocation of all other investors is optimal (see equation (13)).

2. Total demand corresponds to the complete initial endowment of all investors (market clearance).
Due to the law of Walras it is sufficient under market clearance to take into account only the risky assets. If an equilibrium exists there, then an equilibrium also exists for riskless assets.

Let us now take a glance at the individual utility maximization problem. We know the expected value and the variance in the assets' cash flows. The typical maximization problem appears in the following form:

$$
\begin{aligned}
& \max _{X_{0}^{i}, X^{i}} U^{i}\left(\mu \left[X_{0}^{i}+\sum_{n=1}^{N} X^{i} \widetilde{Y}_{n}-\right.\right. \\
& -\tau\left(X_{0}^{i}-p\left(\bar{X}_{0}^{i}\right)+\sum_{n=1}^{N} X_{n}^{i} \widetilde{Y}_{n}-p\left(\bar{X}^{i}\right)\right) \\
& \left.+\omega^{i} \tau \sum_{j=1}^{I}\left(X_{0}^{j}-p\left(\bar{X}_{0}^{j}\right)+\sum_{n=1}^{N} X_{n}^{j} \widetilde{Y}_{n}-p\left(\bar{X}^{j}\right)\right)\right], \\
& \left.\sigma^{2}\left[(1-\tau) \sum_{n=1}^{N} X_{n}^{i} \widetilde{Y}_{n}+\omega^{i} \tau \sum_{j=1}^{I} \sum_{n=1}^{N} X_{n}^{j} \widetilde{Y}_{n}\right]\right) .
\end{aligned}
$$

The argument of the variance function can be simplified because the risk-free asset and the price of the portfolio are irrelevant. Taking into account that the return flow of the riskless asset has been normalized to the value 1 and based on equation (4), the budget constraint of the $i$-th market participant can be written out as follows:

$$
\frac{X_{0}^{i}}{1+r_{f}}=p\left(\bar{X}_{0}^{i}\right)+p\left(\bar{X}^{i}\right)-p \cdot X^{i} .
$$

We can simplify the problem since we know the expected value and the covariance matrix. If we additionally take into account that both

(9) $\quad \sum_{j=1}^{I} X^{j}=1$ and $\sum_{j=1}^{I} X_{0}^{j}=0$

must apply for the equilibrium, the optimization problem can be rewritten in the form:

$$
\text { (10) } \begin{aligned}
\max _{X_{0}^{i}, X^{i}} & U^{i}\left(X_{0}^{i}+X^{i} \cdot E-\right. \\
& -\tau\left(X_{0}^{i}-p\left(\bar{X}_{0}^{i}\right)+\left(X^{i} \cdot E-p\left(\bar{X}^{i}\right)\right)\right)+ \\
& +\omega^{i} \tau(E-p) \cdot 1 \\
& \left.\left((1-\tau) X^{i}+\omega^{i} \tau\right)^{T} \cdot \Omega \cdot\left((1-\tau) X^{i}+\omega^{i} \tau\right)\right) .
\end{aligned}
$$


Finally we will proceed to solve the side condition (8) for $X_{0}^{i}$ and plug it into the function to be maximized. This will result in

$$
\text { (11) } \begin{aligned}
\max _{X^{i}} & U^{i}\left(\left(1+r_{f}\right)\left(p\left(\bar{X}_{0}^{i}\right)+p\left(\bar{X}^{i}\right)-X^{i} \cdot p\right)+\right. \\
+ & X^{i} \cdot E-\tau\left[\left(1+r_{f}\right)\left(p\left(\bar{X}_{0}^{i}\right)+p\left(\bar{X}^{i}\right)-X^{i} \cdot p\right)-\right. \\
- & \left.p\left(\bar{X}_{0}^{i}\right)+X^{i} \cdot E-p\left(\bar{X}^{i}\right)\right]+\omega^{i} \tau(E-p) \cdot 1, \\
& \left.\left((1-\tau) X^{i}+\omega^{i} \tau\right)^{T} \cdot \Omega \cdot\left((1-\tau) X^{i}+\omega^{i} \tau\right)\right) .
\end{aligned}
$$

The first-order conditions read as follows:

$$
\begin{aligned}
& U_{\mu}^{i}\left(E-\left(1+r_{f}\right) \cdot p-\tau\left(E-\left(1+r_{f}\right) \cdot p\right)\right)+ \\
& +2(1-\tau) U_{\sigma^{2}}^{i} \Omega \cdot\left((1-\tau) X^{i}+\omega^{i} \tau\right)=0
\end{aligned}
$$

After cancellations of $1-\tau$ the result will be

$$
\begin{aligned}
& U_{\mu}^{i}\left(E-\left(1+r_{f}\right) \cdot p\right)+ \\
& \quad+2 U_{\sigma^{2}}^{i} \Omega \cdot\left((1-\tau) X^{i}+\omega^{i} \tau\right)=0,
\end{aligned}
$$

whereby the arguments of the utility functions (expected value and variance) are provided by

$$
\begin{aligned}
& \mu(X)=\left(1+r_{f}\right)\left(p\left(\bar{X}_{0}^{i}\right)+p\left(\bar{X}^{i}\right)-X^{i} \cdot p\right)+ \\
& +X^{i} \cdot E-\tau\left[\left(1+r_{f}\right)\left(p\left(\bar{X}_{0}^{i}\right)+p\left(\bar{X}^{i}\right)-X^{i} \cdot p\right)\right. \\
& \left.-p\left(\bar{X}_{0}^{i}\right)+X^{i} \cdot E-p\left(\bar{X}^{i}\right)\right]+\omega^{i} \tau(E-p) \cdot 1
\end{aligned}
$$

and

(15) $\sigma^{2}(X)=\left((1-\tau) X^{i}+\omega^{i} \tau\right)^{T} \cdot \Omega$.

$$
\cdot\left((1-\tau) X^{i}+\omega^{i} \tau\right) \text {. }
$$

Equation (13) is the starting point for our next considerations.

\subsection{Vanishing Risk-free Rate}

Proposition 2.1 (vanishing risk-free inter-

est rate) The risk-free interest rate is zero.

We look at an equilibrium $p$ and $\left(X_{0}^{i}, X^{i}\right)_{i=1 \ldots, I}$ at the tax rate of $\tau>0$. We then deal with an allocation $\left(Z_{0}^{i}, Z^{i}\right)_{i=1, \ldots, I}$ from (20) whereby $p$ and this allocation also constitute an equilibrium at a tax rate of $\tau=0$.

Please note that we do not show the uniqueness of equilibrium prices. Statements on uniqueness in the CAPM can be found in Hens, Laitenberger, and Loeffler (2002). Bottazzi, Hens, and Loeffler (1998) show that the CAPM typically possesses many equilibria. Hence it is possible that various equilibria with different prices can exist at tax rates of $\tau>0$ or even $\tau=0$. We will show that at least one of the possible equilibria must have the price vector $p$.

The result of the theorem is intuitive. A riskless interest rate of zero is effectively equivalent to interest-corrected profit taxation (see Wenger 1983). For a considerable time it has been known that this tax is investment-neutral and therefore has no influence on the prices of goods in the equilibrium. Thus this result does not come as a surprise, and it is independent of the particular redistribution system.

\section{Proof:}

We take the first-order conditions according to (13) and set the interest rate to zero. As a result we have

$$
U_{\mu}^{i}(E-p)+2 U_{\sigma^{2}}^{i} \Omega \cdot\left((1-\tau) X^{i}+\omega^{i} \tau\right)=0,
$$

and the utility function arguments are simplified to

$$
\begin{aligned}
\mu(X)= & p\left(\bar{X}_{0}^{i}\right)+p\left(\bar{X}^{i}\right)+ \\
& +\left((1-\tau) X^{i}+\omega^{i} \tau\right)^{T} \cdot(E-p) \\
\sigma^{2}(X)= & \left((1-\tau) X^{i}+\omega^{i} \tau\right)^{T} \cdot \Omega \\
& \cdot\left((1-\tau) X^{i}+\omega^{i} \tau\right)
\end{aligned}
$$

On the basis of this maximization condition it becomes evident that every equilibrium with a tax rate $\tau>0$ has a corresponding equilibrium with the tax rate $\tau=0$ possessing the same prices for risky assets. We assume that the allocation $\left(X_{0}^{i}, X^{i}\right)$ and the price vector $p$ describe an equilibrium for $\tau>0$. Moreover, if we define

$$
\begin{array}{r}
\forall n>0 \quad Z_{n}^{i}:=X_{n}^{i}(1-\tau)+\omega^{i} \tau \quad \text { and } \\
Z_{0}^{i}:=p\left(\bar{X}_{0}^{i}\right)+p\left(\bar{X}^{i}\right)-Z^{i} \cdot p
\end{array}
$$

we can show that this allocation leads to an equilibrium when the price vector $p$ remains unchanged, provided $\tau=0$. In particular we must verify the following:

1. The aggregate demand is identical to the aggregate supply (market clearance). 
2. Investor $i$ is able to acquire the portfolio $\left(Z_{0}^{i}, Z^{i}\right)$ with an optimal utility for themselves.

Based on the law of Walras we can restrict our considerations to the market for risky assets. All markets for risky financial assets are cleared because we assume

(20) $\forall n>0 \quad \sum_{j=1}^{I} Z_{n}^{j}=\sum_{j=1}^{I}\left((1-\tau) X_{n}^{i}+\omega^{i} \tau\right)=1$.

It is obvious that investor $i$ abides by their budget constraint. We therefore only need to verify that this portfolio maximizes their individual utility. For this purpose we assume that portfolio $X^{i}$ is optimal. It then fulfills the first-order condition at $\tau>0$ according to equation (16). To validate whether portfolio $Z^{i}$ is optimal - in the event that the tax rate vanishes - we let this portfolio take the place of $X^{i}$ in the equation (16) and also employ $\tau=0$. As a result we receive

$$
U_{\mu}^{i}(E-p)+2 U_{\sigma^{2}}^{i} \Omega \cdot\left(Z^{i}\right)=0
$$

with the new arguments

$$
\begin{aligned}
& \text { (22) } \mu(Z)=p\left(\bar{X}_{0}^{i}\right)+p\left(\bar{X}^{i}\right)+\left(Z^{i}\right)^{T} \cdot(E-p), \\
& \text { (23) } \sigma^{2}(Z)=\left(Z^{i}\right)^{T} \cdot \Omega \cdot\left(Z^{i}\right) .
\end{aligned}
$$

This equation is in fact fulfilled for $Z^{i}=(1-\tau) X^{i}+$ $\omega^{i} \tau$ by means of construction. This is what we intended to show.

Konrad (1991) found a neutrality result that seems comparable to our theorem. In fact his result differs in an important aspect from our model. Konrad allows opportunity costs to be deducted from the tax base. This is a tax first advocated by Johansson and Samuelson (taxation of economic gain). Our model is much closer to the tax systems currently in place in most countries.

\subsection{CARA Utility Functions}

The literature typically discusses the concept of absolute risk aversion within the scope of the expected utility theory. However, it can also be defined within $\mu-\sigma$ utility functions. For this purpose let us take a look at the quotient

(24) $S^{i}:=\frac{U_{\mu}^{i}}{U_{\sigma^{2}}^{i}}$
The function features constant absolute risk aversion when the quotient $S^{i}$ is not dependent on the expected value $\mu$, but rather dependent on the variance $\sigma^{2}$ (see proposition 3 in Lajeri-Chaherli and Nielsen 1993 or property 5 in Meyer 1987).

Proposition 2.2 (CARA utility function) The investors have functions with constant absolute risk aversion. Moreover, $p$ and $\left(X_{0}^{i}, X^{i}\right)_{i=1 \ldots, I}$ constitute an equilibrium for the tax rate $\tau>0$. Then we have an allocation $\left(Z_{0}^{i}, Z^{i}\right)_{i=1, \ldots, I}$ as in (29) in such a way that $p$ and this allocation constitute an equilibrium for the tax rate $\tau=0$.

This result, too, is easily explained intuitively. In the case of constant absolute risk aversion the optimal supply of risky assets remains constant when the investor's income is subject to changes (no income effects). Hence the income tax has no influence on the risky portion of the optimal portfolio, since the risky assets are taxed proportionally and the redistribution affects the endowment of the risk-free assets. If, however, the optimal risky assets are identical to a situation without taxes, we conclude from the law of Walras that also the optimal risk-free assets must be in an equilibrium.

\section{Proof:}

Due to $r_{f}>0$ we now have $p_{0}<1$. The adequate conversion of the first-order condition (13) gives us

(25) $\frac{U_{\mu}^{i}}{U_{\sigma^{2}}^{i}}\left(E-\frac{p}{p_{0}}\right)-2 \Omega \cdot\left((1-\tau) X^{i}+\omega^{i} \tau\right)=0$.

After aggregation through all investors and by taking the market clearance into account we will obtain

(26) $\left(E-\frac{p}{p_{0}}\right) \sum_{i=1}^{I} \frac{U_{\mu}^{i}}{U_{\sigma^{2}}^{i}}=2 \Omega \cdot 1$.

At a constant risk aversion quotients are only dependent on the variance

(27) $\left((1-\tau) X^{i}+\omega^{i} \tau\right)^{T} \cdot \Omega \cdot\left((1-\tau) X^{i}+\omega^{i} \tau\right)$.

To prove that the tax rate has no influence on the prices of risky assets, we will - under Walras' law - concentrate on the risky assets and assume that the allocation $\left(X^{i}\right)_{i=1, \ldots, I}$ and the price vector $p$ constitute an equilibrium. Then for these allocations and a tax rate of $\tau>0$ the first-order conditions 
in compliance with (25) have been met for every investor. Hereby we are dealing with the quotients $\frac{U_{\mu}^{i}}{U_{\sigma^{2}}^{i}}$ at the position

$$
\begin{aligned}
\sigma^{2}(X)=\left((1-\tau) X^{i}+\omega^{i} \tau\right)^{T} \cdot \Omega \\
\cdot\left((1-\tau) X^{i}+\omega^{i} \tau\right)
\end{aligned}
$$

Now we deal with the case without taxes. Let the equilibrated allocation be designated as $\left(Z^{i}\right)_{i=1, \ldots, I}$. The first-order condition must be fulfilled for this allocation as well and this time $\tau=0$ applies. However, the tax rate only appears in the argument of the condition. We now select

(29) $Z^{i}:=(1-\tau) X^{i}+\omega^{i} \tau$,

and as a result equation (25) applies trivially. The budget constraints are met, because the risk-free asset is selected precisely in such a way that one can purchase the risk-free portfolio. The market will continue to be cleared since

(30) $\sum_{i=1}^{I} Z^{i}=\sum_{i=1}^{I}(1-\tau) X^{i}+\omega^{i} \tau=1$.

We have thus attained an equilibrium at the price $p$.

At the beginning of this section we referred to the concept of absolute risk aversion (CARA) that is typically used with expected utility. The literature on CARA is manifold (see, e.g., Meyer 1987). Characteristics of relative risk aversion within expected utility are discussed, e.g., in Katz (1983), Briys and Eeckhoudt (1985), and Hey (1985). The case of relative risk aversion is also intensely discussed. Going back to Mehra and Prescott (1985) it is usually stated that constant relative risk aversion (CRRA) is a reasonable assumption. Sinn (1989, p. 162) has concluded, that CRRA are the only utility functions that are compatible with empirical results of psychological experiments. Therefore, one could justifiably ask why we do not apply CRRA-functions here. The answer is simply that within the $\mu-\sigma^{2}$ calculus there are no functions with a constant relative risk aversion (for a proof see Loeffler 1996a p. 32 f.).

\subsection{Two Further Examples}

If we want to generate the result according to which prices are dependent on the tax rate, then the riskfree interest rate may not vanish and there may be no CARA utility functions.
For such an example we examine just one single risky asset and two investors. One of the two decision-makers owns a risky asset; the other owns nothing. The matrix $\Omega$ degenerates to the variance of the risky asset; for simplicity the matrix is set to 1 . As a consequence $E$ and $p$ are numbers.

The utility function for both investors is identical and should be

(31) $U\left(\mu, \sigma^{2}\right)=\frac{\mu}{1+\sigma^{2}}$.

It is strictly quasi-concave and thus satisfies the requirements needed for a unique solution of the maximization calculation. Starting from (13) the FOC for every investor is as follows:

$$
\begin{aligned}
& 0=\frac{E-\left(1+r_{f}\right) p}{1+\sigma^{2}}- \\
& \quad-2\left((1-\tau) X^{i}+\omega^{i} \tau\right) \frac{\mu}{\left(1+\sigma^{2}\right)^{2}} .
\end{aligned}
$$

Simplifying and inserting the arguments for $\mu$ and $\sigma$ (considering that the initial endowment of riskfree asset is zero) leads us to

$$
\text { (33) } \begin{aligned}
(E & \left.-\left(1+r_{f}\right) p\right)\left(1+\left((1-\tau) X^{i}+\omega^{i} \tau\right)^{2}\right)= \\
= & 2\left((1-\tau) X^{i}+\omega^{i} \tau\right)\left[\left(1+r_{f}(1-\tau)\right) p\left(\bar{X}^{i}\right)+\right. \\
& \left.+(1-\tau) X^{i} \cdot\left(E-\left(1+r_{f}\right) p\right)+\omega^{i} \tau(E-p)\right] .
\end{aligned}
$$

We substitute $Z^{i}:=(1-\tau) X^{i}+\omega^{i} \tau$ and formulate the equation as follows:

$$
\begin{aligned}
0=\left(Z^{i}\right)^{2}+2 Z^{i} & \left(\frac{1+r_{f}(1-\tau)}{E-\left(1+r_{f}\right) p} p\left(\bar{X}^{i}\right)+\right. \\
& \left.+\omega^{i} \tau \frac{r_{f} p}{E-\left(1+r_{f}\right) p}\right)-1
\end{aligned}
$$

This is a quadratic equation with the unknown $Z^{i}$ which can be solved. The solution is dependent on the initial endowment. One of the investors owns a share (i.e. $p\left(\bar{X}^{i}\right)=p$ ), the other owns nothing (i.e. $\left.p\left(\bar{X}^{i}\right)=0\right)$.

\section{Investor with one share as initial endow- ment}

The solution of the equation reads

$$
\begin{aligned}
Z^{1}= & -\frac{1+r_{f}(1-\tau)+\tau r_{f} \omega^{1}}{E-\left(1+r_{f}\right) p} p_{ \pm} \\
& \pm \sqrt{\left(\frac{1+r_{f}(1-\tau)+\omega^{1} \tau r_{f}}{E-\left(1+r_{f}\right) p} p\right)^{2}+1}
\end{aligned}
$$




\section{Investor without a share as initial endow- ment}

The solution of the equation reads

$$
\begin{aligned}
Z^{2}= & -\frac{1+r_{f}(1-\tau)+p \tau r_{f} \omega^{2}}{E-\left(1+r_{f}\right) p} \pm \\
& \pm \sqrt{\left(\frac{1+r_{f}(1-\tau)+p \tau r_{f} \omega^{2}}{E-\left(1+r_{f}\right) p}\right)^{2}+1}
\end{aligned}
$$

As a consequence of the market clearance and $\omega^{1}+\omega^{2}=1$ and after the addition of both portfolios and some rearrangement, the following results:

$$
\begin{aligned}
& \text { (37) } \quad E+1+r_{f}(1-\tau)= \\
& = \pm \sqrt{\left(\left(1+r_{f}(1-\tau)+\omega^{1} \tau r_{f}\right) p\right)^{2}+\left(E-\left(1+r_{f}\right) p\right)^{2}} \\
& \pm \sqrt{\left(1+r_{f}(1-\tau)+p \tau r_{f} \omega^{2}\right)^{2}+\left(E-\left(1+r_{f}\right) p\right)^{2}} .
\end{aligned}
$$

For the event of a uniform distribution of tax revenue $\omega^{i}=\frac{1}{2}$ we have determined a numerical solution, as shown in the table below. The other parameters are $r_{f}=5 \%, E=2$. Although two solutions result, one of them leads straight to a return of $5 \%$ for the risky assets and is therefore economically meaningless. It is evident that the price is contingent on the tax rate. In our model all

Table 1: Contingency of equilibrium price $p$ on the tax rate $\tau$

\begin{tabular}{ll}
\multicolumn{1}{c}{$\boldsymbol{\tau}$} & $\boldsymbol{p}$ \\
\hline $0 \%$ & 0.7497 \\
\hline $10 \%$ & 0.7515 \\
\hline $20 \%$ & 0.7532 \\
\hline $30 \%$ & 0.7550 \\
\hline $40 \%$ & 0.7567 \\
\hline $50 \%$ & 0.7585 \\
\hline $60 \%$ & 0.7603 \\
\hline $70 \%$ & 0.7620 \\
\hline $80 \%$ & 0.7638 \\
\hline $90 \%$ & 0.7656
\end{tabular}

investors had the same tax rate. This assumption is of particular importance for our results. It is easy to demonstrate that with a heterogenous taxation prices will depend on the tax rate. To this end we assume that there is only one risky asset. $\Omega, p$, and $E$ degenerate to real numbers. Furthermore, we assume that investor 1 bears no tax $\left(\tau^{1}=0\right)$ and investor 2 is fully taxed $\left(\tau^{2}=\tau\right)$. Both investors have utility functions of the form $U=\mu-\frac{1}{2} \sigma^{2}$. Then we have

$$
0=E-\left(1+r_{f}\right) p+\Omega X^{1}
$$

for the first investor and

(39) $0=E-\left(1+r_{f}\right) p+\Omega\left((1-\tau) X^{2}+\omega^{2} \tau\right)$

for the second one. Additionally, $X^{1}+X^{2}=1$ must hold in equilibrium. From these three equations

(40) $\frac{\left(1+r_{f}\right) p-E}{\Omega}=\omega^{2} \frac{\tau}{2-\tau}$

can be concluded by some simple rearrangement. Obviously, the price depends on the tax rate.

\section{Conclusion}

Authors contributing to the tax CAPM discussion usually neglect the fact that the Treasury typically redistributes the tax revenues that were collected from investors. Whereas this may be acceptable for a partial model, it is certainly unacceptable for a total model. Surprisingly, this aspect has been overlooked by a large number of authors. Based on a total model that contained the redistribution we can show that equilibrium security prices are not affected by taxation, if either the riskless rate vanishes or investors show constant absolute risk aversion. Both results can be explained by economic reasoning. However, neither vanishing interest rates nor CARA utility functions are realistic cases. Since there seems to be no way to extend our results beyond those two special cases, we conclude as a rule that taxes do have an impact on security prices in the CAPM as a rule. Further research should try to reveal whether this impact is substantial or negligible.

\section{References}

Bottazzi, Jean-Marc, Thorsten Hens, and Andreas Löffler (1998): Market Demand Functions in the Capital Asset Pricing Model, Journal of Economic Theory, 79 (2): 192-206.

Brennan, Michael J. (1970): Taxes, Market Valuation and Corporate Financial Policy, National Tax Journal, 23: 417-427.

Briys, Eric and Louis Eeckhoudt (1985): Relative Risk Aversion in Comparative Statics: Comment, American Economic Review, 75 (1): 281-283.

Buchholz, Wolfgang and Kai A. Konrad (200o): Risiko und Steuern, in: Wolfgang Buchholz and Alois Oberhauser (eds.): Probleme der Besteuerung, 3, Duncker \& Humblot: Berlin, 63-139.

Eikseth, Hans M. and Snorre Lindset (2009): A Note on Capital Asset Pricing and Heterogeneous Taxes, Journal of Banking and Finance, 33 (3): 573-577.

Hens, Thorsten, Jörg Laitenberger, and Andreas Löffler (2002): Two Remarks on the Uniqueness of Equilibria in the CAPM, Journal of Mathematical Economics, 37 (2): 123-132. 
Hey, John D. (1985): Relative Risk Aversion in Comparative Statics: Comment, American Economic Review, 75 (1): 284285 .

Jonas, Martin, Andreas Löffler, and Jörg Wiese (2004): Das CAPM mit deutscher Einkommensteuer, Die Wirtschaftprüfung, 57 (17): 898-906.

Katz, Eliakim (1983): Relative Risk Aversion in Comparative Statics, American Economic Review, 73 (3): 452-453.

König, Rolf J. (1990): Ausschüttungsverhalten von Aktiengesellschaften, Besteuerung und Kapitalmarktgleichgewicht, Steuer- und Wirtschaftsverlag: Hamburg.

Konrad, Kai A. (1991): Risk Taking and Taxation in Complete Capital Markets, The Geneva Papers on Risk and Insurance Theory, 16 (2): 167-177.

Lajeri-Chaherli, Fatma and Lars T. Nielsen (1993): Risk Aversion and Prudence, Working Paper, INSEAD.

Lintner, John (1965): The Valuation of Risky Assets and the Selection of Risky Investments in Stock Portfolios and Capital Budgets, The Review of Economics and Statistics, 47 (1): 13-37.

Litzenberger, Robert H. and Krishna Ramaswamy (1979): The Effect of Personal Taxes and Dividends on Capital Asset Prices: Theory and Empirical Evidence, Journal of Financial Economics, 7 (2): 163-195.

Litzenberger, Robert H. and Krishna Ramaswamy (1980): Dividends, Short Selling Restrictions, Tax-Induced Investor Clienteles, and Market Equilibrium, The Journal of Finance, 35 (2): 469-482.

Löffler, Andreas (1996a): Capital Asset Pricing Model mit Konsumtion: Eine gleichgewichtstheoretische Untersuchung, Deutscher Universitäts-Verlag: Wiesbaden.

Löffler, Andreas (1996b): Variance Aversion Implies $\mu-\sigma^{2}$ Criterion, Journal of Economic Theory , 69 (2): 532-539.

Mehra, Rajnish and Edward C. Prescott (1985): The Equity Premium: A Puzzle, Journal of Monetary Economics, 15 (2): 145-161.

Meyer, Jack (1987): Two-Moment Decision Models and Expected Utility Maximization, American Economic Review, 77 (3): 421-430.

Mossin, Jan (1996): Equilibrium in a Capital Asset Market, Econometrica, 34 (4): 768-783.

Rapp, Marc S. and Bernhard Schwetzler (2007): Das Nachsteuer-CAPM im Mehrperiodenkontext: Stellungnahme zum Beitrag von Dr. Jörg Wiese, FinanzBetrieb, 2007 (2): 108-116.

Rapp, Marc S. and Bernhard Schwetzler (2008): Equilibrium Security Prices with Capital Income Taxes and an Exogenous Interest Rate, Finanzarchiv, 64 (3): 425-442.

Sharpe, William F. (1964): Capital Asset Prices: A Theory of Market Equilibrium under Conditions of Risk, The Journal of Finance, 19 (3): 425-442.

Shell, Karl (forthcoming): Sunspot Equilibria, in: Steven Durlauf and Lawrence Blume (eds.): The New Palgrave: A Dictionary of Economics, Palgrave Macmillan: New York.

Sinn, Hans-Werner (1989): Economic Decisions under Uncertainty, 2nd ed., Physica: Heidelberg.

Stiglitz, Joseph E. (1972): Taxation, Risk Taking, and the Allocation of Investment in a Competitive Economy, in: Michael C. Jensen (ed.): Studies in the Theory of Capital Markets, Praeger: New York et al. , 294-374.
Wenger, Ekkehard (1983): Gleichmäßigkeit der Besteuerung von Arbeits- und Vermögenseinkünften, Finanzarchiv, 41 (2): 207-252.

Wiese, Jörg (2004): Unternehmensbewertung mit dem Nachsteuer-CAPM?, Working Paper, Ludwig-MaximiliansUniversität: München.

Wiese, Jörg (2006a): Das Nachsteuer-CAPM im Mehrproduktkontext, FinanzBetrieb, 2006 (4): 42-248.

Wiese, Jörg (2006b): Komponenten des Zinsfußes in Unternehmensbewertungskalkülen: Theoretische Grundlage und Konsistenz, Lang: Frankfurt/Main.

Wiese, Jörg (2007): Unternehmensbewertung und Abgeltungssteuer, Die Wirtschaftsprüfung, 60 (9): 368-375.

\section{Biographies}

Lutz Kruschwitz is chair of Banking and Finance at the Freie Universität Berlin since 1991. He was born in 1943 in Berlin, Germany, and is a graduate in business administration from the Freie Universität Berlin. Kruschwitz received his doctoral degree in 1970 and his Habilitation (postdoctoral lecture qualification) in 1975 . His research interests include corporate finance and valuation theory in particular. He holds an Honorary Doctorate from the University of Tübingen, Germany, and is serving as Honorary Professor at the University of Vienna, Austria.

Andreas Löffler is chair of Finance and Investment at the University of Paderborn since 2008. He was born in 1964 in Szeged, Hungary, and is a graduate in mathematics from the University of Leipzig. Löffler received his first doctoral degree in mathematics in 1992, his second doctoral degree in 1995 and his Habilitation in 1999. His research interests include decision theory, equilibrium theory and valuation theory. 